\title{
Effects of Yoga Therapy and Walking Therapy in Reducing Blood Sugar Levels on Diabetes Mellitus Patients in the Community
}

\author{
Wachidah Yuniartika ${ }^{1 *} \mathbb{D}$, Agus Sudaryanto ${ }^{1}$, Abi Muhlisin $^{1}$, Dian Hudiyawati ${ }^{2}$, Dimas Ria Angga Pribadi ${ }^{2}$ \\ ${ }^{1}$ Department of Community and Family Nursing, Faculty of Health Sciences, Muhammadiyah University, Surakarta, Indonesia; \\ ${ }^{2}$ Department of Medical and Surgical Nursing, Faculty of Health Sciences, Muhammadiyah University, Surakarta, Indonesia
}

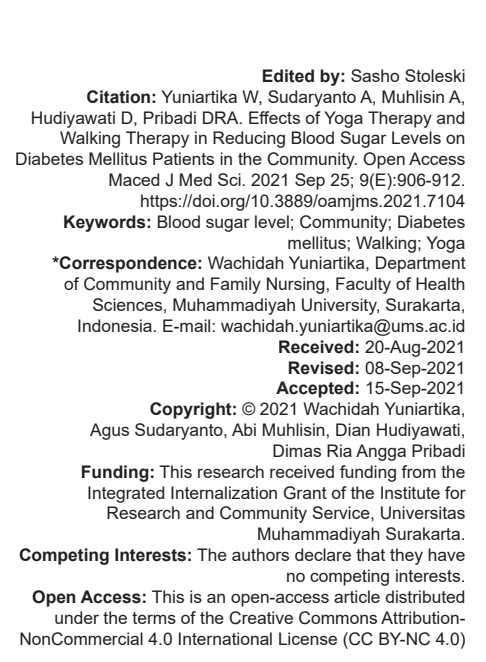

Abstract

BACKGROUND: The increasing of diabetes mellitus cases in Indonesia may be due to changes in people's lifestyles, which is lack of exercise. Factors that may contribute to the high prevalence of diabetes mellitus sufferers other than genetics are exacerbated by environmental factors. Exercise interventions have been effective in counterbalancing diabetes complications. Yoga exerts a beneficial effect on insulin kinetics and the resulting lipid profile. Yoga helps redistribute body fat and reduces obesity which may lead to insulin resistance. In addition, other types of physical activity that can be done by diabetes mellitus patients are adequate morning walking while having scenery leisure for $30 \mathrm{~min}$ or more.

AIM: This study was conducted to determine the effect of yoga therapy and walking therapy on diabetes mellitus patients in the community.

METHODS: Quantitative research using randomized control trial, conducted in Gedongan Village, Baki Subdistrict, Sukoharjo Regency, involving 54 samples divided into three groups. Inclusion criteria: Patients with type 2 diabetes mellitus, fasting glucose levels of $126 \mathrm{mg} / \mathrm{dl}$, no complication, and no insulin therapy or diabetes medication. The outcome measured was fasting blood sugar levels. The intervention group performed therapy for 12 weeks with a duration of 3 times a week.

RESULTS: The average fasting sugar levels in the yoga group pre (217.00) post (187.72) p (0.001), the walking group averaged pre (209.89) post (193.83) p (0.001), and the control group averaged pre (221.50) post (225.17) $\mathrm{p}(0.067)$.

CONCLUSION: There was an effect of yoga therapy and walking therapy on reducing fasting glucose levels.

\section{Introduction}

Diabetes mellitus is a common non-communicable disease and its prevalence is increasing every year worldwide. There are 463.0 million people suffering from diabetes in 2019 globally with a vulnerable population of 20-79 years and it is estimated that in 2045 there will be an increase in diabetes cases to 700.2 million people. Data from the International Diabetes Federation in 2019 revealed that 10.7 million diabetes mellitus sufferers in Indonesia were ranked $7^{\text {th }}$ in the world, and it is estimated that by 2045 this case will rise to $8^{\text {th }}$ place with 16.6 million diabetes mellitus people [1]. Diabetes affects more than 29 million adults in America and is the seventh leading cause of death in the United States. The American Diabetes Association encloses that regular physical activity is essential for blood glucose management and health for individuals with type 2 diabetes [2].

The increasing cases of diabetes mellitus in Indonesia may be triggered by changes in people's lifestyles, which is lack of exercise. Factors that may contribute to the high prevalence of diabetes mellitus sufferers other than genetics are exacerbated by environmental factors, including rising prosperity and urbanization which result in increased obesity and insulin resistance. Exercise interventions have been effective in counterbalancing diabetes complications. By modifying muscle fibers and improving beta-cell function, exercise can optimize insulin sensitivity and improve glucose intolerance. Thus, exercise may be particularly effective in the early stages of the disease [3].

Physical activity may increase high-density lipoprotein levels and reduce cholesterol and triglyceride concentrations. However, patients with diabetes mellitus are usually unable to maintain the level of recommended physical activity due to various reasons such as age, obesity, cardiovascular disease, and other complications. One of the physical activities that can be performed by diabetes mellitus patients is Yoga Therapy. Yoga exerts a beneficial effect on insulin kinetics and the resulting lipid profile. Yoga helps redistribute body fat and decreases obesity which may lead to insulin resistance [4].

In developed countries, the United States, for instance, $80 \%$ of the population practice yoga to 
maintain health and prevent disease. Yoga therapy is a body and mind exercise that focuses on strength, breathing, and flexibility to improve body health. Yoga may help people with various chronic diseases and alleviate their quality of life as in people with diabetes mellitus; yoga can lower blood sugar levels in the body.

Yoga may balance and harmonize the body, mind, and emotions. Yoga practice is a complex intervention consisting of various components including cleansing processes (kriya), postures (asana), breathing control (pranayama), meditation, and relaxation. Asanas are movements to emphasize the connection of body, mind, and consciousness focusing on synchronizing breathing and movement. The key to practicing yoga postures is to do it with balance and tranquility. Sitting posture in yoga may improve pancreatic function. Asana with forward bending massage serves to put pressure on the pancreas and stimulate insulin secretion. For medicinal benefits, yoga poses need to be maintained for approximately $30 \mathrm{~s}$ to $1 \mathrm{~min}$ depending on the individual and the duration may be multiplied gradually. A study shows that yoga postures have a positive effect on glucose utilization and fat redistribution in individuals with type 2 diabetes [5]. Yoga sessions for those with diabetes mellitus can be rehearsed for $60 \mathrm{~min}$ and twice a week. On other days, people with diabetes can do the exercises themselves at home. The 60-min session consists of $25 \mathrm{~min}$ of Surya namaskara, $12 \mathrm{~min}$ of walking, 5-7 min of muscle relaxation, and $15 \mathrm{~min}$ of asanas or yoga postures [6].

Furthermore, other types of physical activity that can be followed by people with diabetes mellitus are adequate morning walking while having scenery leisure for $30 \mathrm{~min}$ or more and done for at least 3-4 times a week [7]. The effect of physical activity or exercise is directly related to an increase in the speed of muscle glucose recovery (how much muscle takes glucose from the bloodstream). During exercise, the muscles use the glucose stored within and when the glucose is depleted, the muscles fill the void by taking glucose from the blood. This sequence will result in a decrease in blood glucose thereby increasing blood glucose control [8]. The great benefits of physical activity or exercise in diabetes mellitus comprise lowering blood glucose levels, preventing obesity, overcoming complications, blood lipid disorders, and increasing blood pressure [9]. The novelty of this research is that the implementation of yoga therapy in this research employed a combination of materials from the concept of yoga, progressive relaxation, and spiritual therapy so that besides being able to balance the body condition, the patients can control emotions.

Based on the results of a preliminary study conducted at the Community Health Center of BakiSubdistrict, it found 940 people with diabetes mellitus in 2019. This figure indicates a growth of around $90 \%$ from the number of diabetes mellitus cases in 2018 in Baki Community Health Center. Departing from existing data in Gedongan Village, Baki Subdistrict, there are approximately 201 people with diabetes mellitus in 2020 and this number has shown increased by about $59 \%$ from 2018 . The purpose of this study is to determine the effect of yoga and walking therapy on diabetes mellitus patients in the community.

\section{Materials and Methods}

\section{Research design}

This study is a quantitative study using a randomized control design. The population is people with diabetes mellitus of adult age involving 201 respondents in Gedongan Village. The number of samples was calculated using the Lemeshow formula and obtained a sample of 54 respondents and added $10 \%$ to anticipate drop out, with the distribution of 18 respondents to the Yoga Therapy Intervention group, 18 respondents to Walking Therapy, and 18 respondents to the control group.

\section{Inclusion criteria}

Patients with type 2 diabetes mellitus (T2DM), fasting glucose levels of $126 \mathrm{mg} / \mathrm{dl}$, have no complications, do not receive insulin therapy or diabetes medication.

\section{Randomization and blinding}

Randomization of participants into the intervention group or control group was carried out by the research assistant administering the technique of putting the participants' name into the envelope. The number of all participants 70 respondents who did not meet the criteria, a total of ten respondents included six respondents who did not meet the inclusion criteria and four respondents did not want to participate in the study, so that participants who met 60 respondents. The study was divided into three groups, namely, the yoga intervention group, the walking therapy intervention group and the control group, each group consisting of 20 respondents, two individuals in yoga therapy were excluded because they did not follow through to completion due to their children and work out of town, and two walking therapy groups were excluded. Due to death and discontinuation of the intervention, and two control groups were excluded due to death. So the number of respondents analyzed there are 18 respondents. Participants were not informed about the group they were in, before the therapy respondents were asked to fill out a research agreement, then each therapy was carried out in a different place and at different times. 


\section{Procedure}

\section{Experimental intervention}

\section{The yoga therapy group}

Yoga group respondents were trained to practice yoga intervention in three 60 -min sessions. The media utilized to train patients were videos and practice manuals, after which respondents were asked to continue therapy at home following videos and accompanied by cadres for 12 weeks with a duration of 3 times a week. Yoga exercises for people with diabetes mellitus consist of: (1) Warm-up 1, the movements included straightening legs, closing right and left feet, and holding the toes with the right palm and then shaking both knees and calves, every movement was done while inhaling. (2) Warming up 2, the movements included straightening legs, placing the hands beside the buttocks, bending the left and right legs like cross-legged, holding the shoulders with the left hand, and holding the back with the right hand while looking to the right side (reverse movement) while inhaling. (3) Core exercises included movement: (1) Dynamic spinal twist, the movement covered sitting upright and then both legs stretched out with a distance while straightening both hands, right hand touching the toes of the left foot and then the left hand behind the back the movement was repeated in the opposite direction while inhaling. (2) Knee bending, sitting upright, then lifting right leg and embracing it with both hands, bending right leg up to the chest. (3) Naukasanchalanan/ rowing, which included straightening legs, making movements resembling rowing a boat. (4) Karmasana sitting movement with legs bent while both fingers tie back when exhaling look to the right/left side, then joining two fingers of hands and lifting them above the head, moving the hand to the left/right side while inhaling. (5) Bhastriksana breathing technique 1 included sitting in meditation and inhaling and exhaling for a count of 8 times. (6) Bhastriksana breathing technique 2, ascetic movements, closing the right nostril with the thumb when inhaling and the left nostril with the ring finger when exhaling. (4) Progressive relaxation included, frowning, tightening the shoulders, tightening the arms, tightening the calves, practicing each movement for 5-7 s while inhaling. (5) Guide Imagery combined with Spiritual Mindfulness was done by closing the eyes while reciting istigfar (seeking forgiveness from Allah) in the heart. (6) Closing movement after praying, rubbing hands until hot, and then wiping it to face.

\section{The walking therapy group}

Respondents in the walking therapy group were instructed to practice walking with a leisurely morning walking from 06.00 to 07.00 for $30 \mathrm{~min}$ and carried out 3 times a week for 12 weeks. During walking therapy, respondents were advised not to have breakfast before. To monitor walking therapy, they were given a checklist of activities and motivated by health cadres.

\section{The control group}

After experiencing high fasting glucose levels, participants were not given direct intervention by the researcher. Participants in the controls were given standard diabetes care by leaflet.

\section{Data collection procedure}

Data were collected in February 2021 with the following procedure (Figure 1):

1. Participants are recruited using data on the Elderly and adult Integrated Healthcare Center

2. Explanation of experimental therapy, then participants are given Informed consent signed by the participants in terms of agreeing to participate in the research

3. Participants were measured fasting blood sugar using a glucometer. The day before, there was information for fasting before the examination

4. Randomization of participants into the intervention group or control group was carried out by the research assistant administering the technique of putting the participants' name into the envelope

5. Participants according to the inclusion criteria were divided into three groups

6. Then, depending on the group of participants assigned to the intervention being taught. Yoga therapy was carried out for 12 weeks, with a duration of 3 times a week with 60 min each session. Walking therapy was carried out for 12 weeks with a duration of 3 times a week with 30 min each session

7. Blood sugar examination after the intervention of the three groups was completed for 12 weeks

8. All data were numerically codified for anonymity and analyzed after collection (Figure 1).

Table 1: Distribution of walking group, yoga group, and control group characteristics by gender, age, education, and occupation

\begin{tabular}{|c|c|c|c|c|c|c|c|}
\hline \multirow[t]{2}{*}{ Characteristics } & \multicolumn{2}{|c|}{ Walking $(n=18)$} & \multicolumn{2}{|c|}{ Yoga $(n=18)$} & \multicolumn{2}{|c|}{ Control $(n=18)$} & \multirow[t]{2}{*}{$p$} \\
\hline & Frequency & $\%$ & Frequency & $\%$ & Frequency & $\%$ & \\
\hline \multicolumn{8}{|l|}{ Gender } \\
\hline a. Male & 5 & 27.8 & 7 & 38.9 & 8 & 44.4 & \multirow[t]{2}{*}{0.116} \\
\hline b. Female & 13 & 72.2 & 11 & 61.1 & 10 & 55.6 & \\
\hline \multicolumn{8}{|l|}{ Age } \\
\hline $40-50$ years & 2 & 11.1 & 8 & 44.4 & 8 & 44.4 & \multirow[t]{4}{*}{0.194} \\
\hline $51-60$ years & 5 & 27.8 & 8 & 44.4 & 9 & 50.0 & \\
\hline $61-70$ years & 7 & 38.9 & 2 & 11.1 & 1 & 5.6 & \\
\hline $\begin{array}{l}71 \text { years and } \\
\text { more }\end{array}$ & 4 & 22.2 & 0 & 0 & 0 & 0 & \\
\hline \multicolumn{8}{|l|}{ Education } \\
\hline Elementary & 7 & 38.9 & 7 & 38.9 & 7 & 38.9 & \multirow[t]{4}{*}{0.073} \\
\hline Junior High & 1 & 5.6 & 5 & 27.8 & 2 & 11.1 & \\
\hline Senior High & 2 & 11.1 & 3 & 16.7 & 5 & 27.8 & \\
\hline $\begin{array}{l}\text { Not in } \\
\text { education }\end{array}$ & 8 & 44.4 & 3 & 16.7 & 4 & 22.2 & \\
\hline \multicolumn{8}{|l|}{ Occupation } \\
\hline Entrepreneur & 2 & 11.1 & 3 & 16.7 & 0 & 0 & \multirow[t]{4}{*}{0.444} \\
\hline Labor & 4 & 22.2 & 9 & 50.0 & 9 & 50.0 & \\
\hline Farmer & 2 & 11.1 & 3 & 16.7 & 3 & 16.7 & \\
\hline Unemployed & 10 & 55.6 & 3 & 16.7 & 6 & 33.3 & \\
\hline \multicolumn{8}{|l|}{ Marital Status } \\
\hline Married & 16 & 88.9 & 14 & 77.8 & 14 & 77.8 & \multirow[t]{2}{*}{0.117} \\
\hline Widow/ & 2 & 11.1 & 4 & 22.2 & 4 & 22.2 & \\
\hline
\end{tabular}




\section{Statistical analyses}

Data were analyzed using SPSS Statistics general data characteristics, frequency, and percentage. The homogeneity of the experimental and control groups used the ANOVA test. The outcome variables among the three groups were analyzed using the Wilcoxon test.

\section{Results}

\section{Demographic characteristics}

There were no significant differences among the three groups concerning general characteristic homogeneity or baseline dependent variables, indicating that the three groups were similar. The majority of walking therapy were 13 women $(72.2 \%)$ and the majority of age ranged from 61 to 70 years with 7 (38.9\%) participants. The majority of education was not in education with $8(44.4 \%)$, most of them did not work $10(55.6 \%)$ and the marital status of the majority was married with a total of $16(88.9 \%)$. The majority of yoga were 11 women $(61.1 \%)$, with most of them in the age range of $40-50$ years $(44.4 \%)$ and $51-60$ years (44.4) with a total of 8 respondents, respectively. The elementary school education was majority with $7(38.9 \%)$, most of them worked as labors with $9(50.0 \%)$ people and the marital status of the majority was married with $14(77.8 \%)$. It can be observed that the majority were ten women $(55.6 \%)$, with most of them in the 51-60 years age comprising nine (50.0\%) people. The elementary school education was the highest with $7(38.9 \%)$, most of them worked as laborers $9(50.0 \%)$, and the marital status of the majority was married with $14(77.8 \%)$ (Table 1$)$.

\section{Primary outcomes}

The results of the analysis in Table 2 show that the average blood sugar level before walking exercise was $160-210 \mathrm{mg} / \mathrm{dl}(66.7 \%)$ with a significance value of 0.041 . Then, the data on average blood sugar levels after walking exercise were $160-210 \mathrm{mg} / \mathrm{dl}(66.7 \%)$ with a significance value of 0.017 . For yoga group, the average blood sugar level before the intervention was
$160-210 \mathrm{mg} / \mathrm{dl}(55.6 \%)$ with a significance value of 0.066 and after the intervention, the blood sugar level was $160-210 \mathrm{mg} / \mathrm{dl}(77.8 \%)$ with a significance value of 0.001 . In the control group, the majority of blood sugar levels showed 160-210 mg/dl (55.6) with a significance value of 0.013 , and after the intervention showed a value of $160-210 \mathrm{mg} / \mathrm{dl}$ (55.6) with a significance value of 0.118 . High blood sugar levels were influenced by several factors, such as an unhealthy lifestyle in the form of lack of physical activity. Regular physical exercise may improve the quality of blood vessels and improve all aspects of blood sugar levels (Table 2).

\section{Secondary outcomes}

The results obtained in the yoga therapy and walking therapy groups showed the value of $p=0.001$ $\leq 0.05$. It can be concluded that there was a significant effect between yoga therapy and walking therapy on changes in blood glucose levels in people with diabetes mellitus. While in the control group, the value of $p=0.067$ $>\alpha=0.05$. It implies that there was no significant effect between the control groups on changes in blood glucose levels in people with diabetes mellitus (Table 3).

\section{Discussion}

Diabetes mellitus affects more women than men and it is predicted that people with diabetes mellitus in the world will continue to grow until 2045. The results of this study are also supported by research [10] that people with diabetes mellitus in Indonesia in 2018 were more likely women (1.8\%) than men (1.2\%). It occurs because women will experience a decrease in postmenopausal estrogen levels and several body functions [1].

The older people, that most of the age range of people with diabetes mellitus is $40-59$ years. It is more vulnerable because age may affect the function and condition of the body physiologically. This result is corroborated by research [11], the prevalence of diabetes mellitus in Indonesia in 2018 shows that the largest diabetes mellitus sufferers are in the 55-74 years age group.

Table 2: Frequency distribution and results of pre- and post-normality test of blood sugar levels

\begin{tabular}{|c|c|c|c|c|c|c|c|c|c|}
\hline \multirow[t]{2}{*}{ Characteristics } & \multicolumn{2}{|c|}{ Walking group } & \multirow{2}{*}{$\begin{array}{l}\text { Normality test } \\
p\end{array}$} & \multicolumn{2}{|c|}{ Yoga group } & \multirow{2}{*}{$\begin{array}{l}\text { Normality test } \\
p\end{array}$} & \multicolumn{2}{|c|}{ Control group } & \multirow{2}{*}{$\begin{array}{l}\text { Normality test } \\
\mathrm{p} \\
\end{array}$} \\
\hline & $(n: 18)$ & $\%$ & & (n: 18) & $\%$ & & (n: 18) & $\%$ & \\
\hline \multicolumn{10}{|c|}{ Blood sugar before intervention } \\
\hline $160-210 \mathrm{mg} / \mathrm{dl}$ & 12 & 66.7 & \multirow[t]{3}{*}{0.041} & 10 & 55.6 & \multirow[t]{3}{*}{0.066} & 10 & 55.6 & \multirow[t]{3}{*}{0.013} \\
\hline $211-261 \mathrm{mg} / \mathrm{dl}$ & 5 & 27.8 & & 4 & 22.2 & & 2 & 11.1 & \\
\hline $262 \mathrm{mg} / \mathrm{dl}$ above & 1 & 5.6 & & 4 & 22.2 & & 6 & 33.3 & \\
\hline \multicolumn{10}{|c|}{ Blood sugar after intervention } \\
\hline $160-210 \mathrm{mg} / \mathrm{dl}$ & 12 & 66.7 & \multirow[t]{3}{*}{0.017} & 14 & 77.8 & \multirow[t]{3}{*}{0.001} & 10 & 55.6 & \multirow[t]{3}{*}{0.118} \\
\hline $211-261 \mathrm{mg} / \mathrm{dl}$ & 6 & 33.3 & & 3 & 16.7 & & 2 & 11.1 & \\
\hline $262 \mathrm{mg} / \mathrm{dl}$ keatas & 0 & 0 & & 1 & 5.6 & & 6 & 33.1 & \\
\hline
\end{tabular}


Table 3: The results of the mean difference between pre-test and post-test

\begin{tabular}{lllll}
\hline Group & \multicolumn{2}{l}{ Analysis result } & $\mathrm{p}$ \\
\cline { 2 - 4 } & Information & $\mathrm{n}$ & Mean \pm SD & \\
\hline Yoga therapy & Pre-test & 18 & $217.00 \pm 47.319$ & 0.001 \\
\multirow{2}{*}{ Walking therapy } & Post-test & 18 & $187.72 \pm 39.823$ & \\
\multirow{3}{*}{ Control } & Pre-test & 18 & $209.89 \pm 36.590$ & 0.001 \\
& Post-test & 18 & $193.83 \pm 31.564$ & \\
& Pre-test & 18 & $221.50 \pm 47.493$ & 0.067 \\
\hline
\end{tabular}

In this study, it was found that the majority of people with diabetes mellitus in Gedongan Village graduated from elementary education as many as seven respondents in the yoga group. It indicates that low education has a greater risk of suffering from diabetes mellitus. This finding is confirmed by research [12] that (58.4\%) people with diabetes mellitus had low education. Diabetes mellitus patients with low education have less knowledge about health than those with higher education levels.

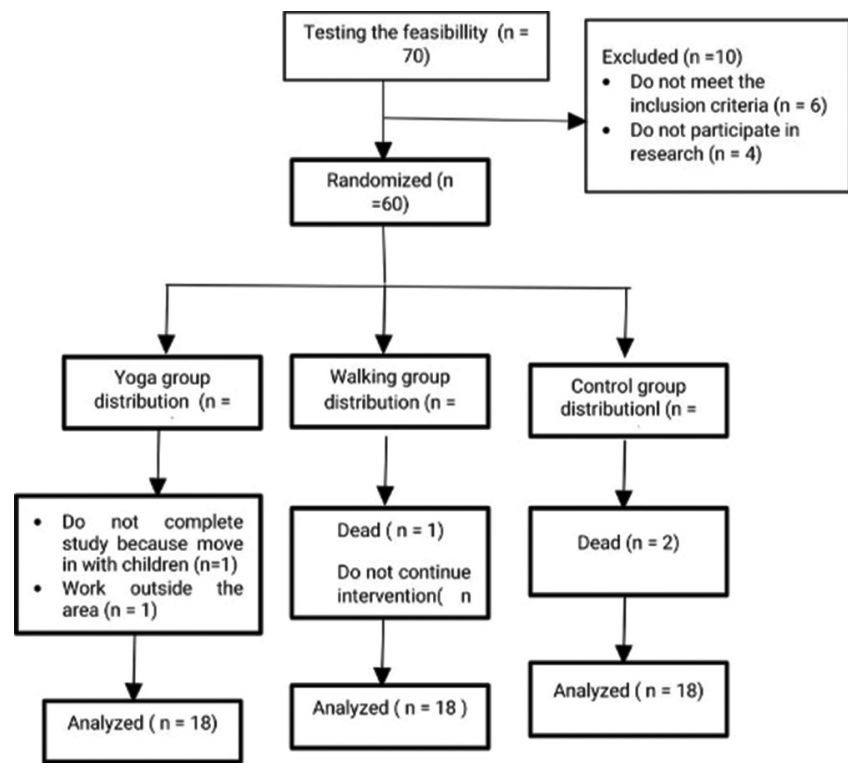

Figure 1: Data collection

This study reveals the results of the marital status of the majority of respondents, encompassing married status with 14 respondents in each group. Given this result, it signifies that marital status has no effect on controlling diabetes mellitus. This result is contradicted to research [12] with the results showing that there were 23 respondents $(62.1 \%)$ with married marital status.

The control group was given the common standard of care including continuing oral hypoglycemic medication, advising diabetic diet and exercising for a minimum of $10 \mathrm{~min}$ a day to a rate of $150 \mathrm{~min} /$ week. All patients were reviewed monthly and required treatment was provided.

Diabetes is a chronic metabolic disease that adversely affects the quality of life. Improved glycemic control is associated with a significant reduction in long-term complications. Oftentimes, pharmacological treatment alone is not sufficient to achieve glycemic control [13]. One-third of diabetic patients use some type of complementary or alternative medicine (CAM) therapy, and about 3-20\% use specific CAM to treat their diabetes [14]. Yoga is one of the most commonly used CAM therapies among adults in the United States [15]. Yoga practices widely used to promote health and manage illness include asanas (physical postures), pranayama (regular breathing), and meditation.

Yoga is increasingly used as an adjunct therapy in the management of T2DM [16]. The advantages of yoga for diabetes management have also been found in recent reviews. Innes and Selfe [15] discovered that yoga could improve glycemic control, lipid levels, and body composition (weight and body mass index [BMI]) in adults with T2DM. The ratio of men to women with diabetes is almost equivalent. Women are often more severely affected by complications of diabetes. The prevalence of overweight and abdominal obesity is also high among women and they also suffer from related complications such as increased lipid and blood sugar levels [6]. Stretching the abdomen during yoga practice is believed to result in the regeneration of pancreatic cells. Various postures during yoga practice help to increase the sensitivity of cells to glucose, thereby increasing insulin secretion and blood supply to muscles and muscle relaxation, resulting in improving glucose absorption [17].

Yoga therapy may reduce blood sugar, body weight, lipid profile, blood pressure, oxidative stress, and cortisol levels. Impaired glucose tolerance can be controlled with yoga therapy that is rehearsed regularly. The results of this control undergo two processes; the hypothalamicpituitary adrenal (HPA) axis and reducing the activation of the sympathoadrenal system. Activation of the HPA axis and the sympathoadrenal system may bring the effect of increasing insulin resistance, inhibiting insulin release, and increasing hepatic glucose production. Besides yoga, there are physical exercises that can be practiced by those with diabetes mellitus, such as aerobics, jogging, walking, diabetes exercise, and cycling [18].

Walking is one type of moderate aerobic exercise, which is acceptable by patients and can be carried out daily [17]. Walking exercise at short-term intervals may improve glycemic control measures derived from continuous glucose monitoring in patients with type 2 diabetes [19]. Other studies have shown that walking may improve glycemic control and BMI in T2DM patients [20]. Walking has been pronounced as one of the most effective exercises in helping diabetes mellitus patients to maintain optimal blood glucose levels. Regular walking has been shown to decrease PAI-1 levels and contribute to the prevention of thrombosis-related vascular complications in diabetes mellitus patients [21].

Walking exercises performed by respondents will lead to an increase in the body's need for fuel by active muscles. In walking exercise, there will be complex bodily reactions including circulation, metabolism, release, and regulation of hormones and the autonomic 
nervous system. At rest, muscle metabolism uses only very little glucose as a fuel source, while during exercise glucose and fat are the main energy sources [22].

Exercise is one of the most important treatment methods besides diabetes mellitus medication. Several studies have shown that physical exercise is an important non-pharmacological intervention in the management of diabetes mellitus patients. Among the various forms of physical exercise, walking is widely accepted by T2DM patients because of its low cost, safety profile, and convenience. It can be performed with different intensities and speeds, does not require special skills, and has relatively minimal side effects [20]. An observational study suggests that the walking intervention may lower glycated hemoglobin levels.

Both moderate and vigorous exercises have been associated with a lower risk of T2DM; however, studies on blood glucose control tend to achieve significant improvements for vigorous and more than moderate physical activity. The benefits of walking, in particular, in reducing the risk of T2DM are well documented. More vigorous exercise appears to produce greater health benefits [23].

\section{Conclusion}

Based on the results presented in this study, Yoga therapy and walking therapy resulted in reducing fasting blood sugar levels in people with diabetes mellitus. This therapy can be used as a non-medical intervention and as additional knowledge for people with diabetes mellitus, families, and health cadres. This can also be carried out independently.

\section{Author's Contributions}

All the authors contributed equally.

\section{Ethical Statement}

The protocol and research ethics have been approved by the ethics committee of the Faculty of Medicine, Universitas Muhammadiyah Surakarta No.3295/B.1/KEPK-FKUMS/I/2021.

\section{Acknowledgment}

The researcher would like to thank the head of the Baki Sukoharjo Community Health Center and the Head of Gedongan Village who have provided permission to conduct the research. We would also thank Mrs. Lusi Hariyanti as the village midwife, Mrs. Parjiyem as the head of the Cadre, and health cadres who helped to motivate therapy to patients.

\section{References}

1. International Diabetes Federation. IDF Diabetes Atlas. $9^{\text {th }}$ ed Brussels, Belgium: International Diabetes Federation; 2019.

2. Bock BC, Thind H, Fava JL, Dunsiger S, Guthrie KM, Stroud L, et al. Feasibility of yoga as a complementary therapy for patients with Type 2 diabetes: The healthy active and in control (HA1C) study. Complement Ther Med. 2019;42:125-31. https:// doi.org/10.1016/j.ctim.2018.09.019

PMid:30670230

3. McDermott KA, Rao MR, Nagarathna R, Murphy EJ, Burke A, Nagendra $\mathrm{RH}$, et al. A yoga intervention for type 2 diabetes risk reduction: A pilot randomized controlled trial. BMC Complement Altern Med. 2014;14:1-14. https://doi. org/10.1186/1472-6882-14-212

PMid:24980650

4. Shantakumari N, Sequeira S, El Deeb R. Effects of a yoga intervention on lipid profiles of diabetes patients with dyslipidemia. Indian Heart J. 2013;65(2):127-31. https://doi. org/10.1016/j.inj.2013.02.010

PMid:23647889

5. Raveendran AV, Deshpandae A, Joshi SR. Therapeutic role of yoga in Type 2 diabetes. Endocrinol Metab. 2018;33(3):307-17. https://doi.org/10.3803/EnM.2018.33.3.307

PMid:30112866

6. Sreedevi A, Gopalakrishnan UA, Ramaiyer SK, Kamalamma L. A Randomized controlled trial of the effect of yoga and peer support on glycaemic outcomes in women with type 2 diabetes mellitus: A feasibility study. BMC Complement Altern Med. 2017;17(1):1-8. https://doi.org/10.1186/s12906-017-1574-x PMid:28173786

7. Lisiswanti R, Novadlu CR. Physical activity in lowering blood glucose levels in Type 2 diabetes mellitus. Majority. 2016;5(3):140-4. https://doi.org/10.15395/mkb.v51n4.1765

8. Barnes SM, Walter $\mathrm{KH}$, Chard KM. Does a history of mild traumatic brain injury increase suicide risk in veterans with PTSD? Rehabil Psychol. 2012;57(1):18-26. https://doi. org/10.1037/a0027007 PMid:22369114

9. Ilyas El. Exercise for diabetes. In: Soegondo S, editor. Integrated Diabetes Mellitus Management for Doctors and Diabetes Educators. Jakarta: Fakultas IImu Komputer Universitas Indonesia; 2011.

10. Kementerian Kesehatan Republik Indonesia. Hari Diabetes Sedunia Tahun 2018 World Diabetes Day 2018. Jakarta, Indonesia: Kementerian Kesehatan Republik Indonesia; 2019.

11. Guariguata L, Whiting DR, Hambleton I, Beagley J, Linnenkamp U, Shaw JE. Global estimates of diabetes prevalence for 2013 and projections for 2035. Diabetes Res 
Clin Pract. 2014;103(2):137-49. https://doi.org/10.1016/j. diabres.2013.11.002

PMid:24630390

12. Kartika P, Livana R. Faktor factors that affect hypertension. J IIm Permas. 2016;6(4):1-10.

13. Kim HJ, Jung TS, Jung JH, Kim SK, Lee SM, Kim KY, et al. Improvement of glycemic control after re-emphasis of lifestyle modification in type 2 diabetic patients reluctant to additional medication. Yonsei Med. J. 2013;54(2):345-51. https://doi. org/10.3349/ymj.2013.54.2.345

PMid:23364966

14. Clarke TC, Black LI, Stussman BJ, Barnes PM, Nahin RL. Trends in the use of complementary health approaches among adults: United States, 2002-2012. Natl Health Stat Report. 2015;79:1-16.

PMid:25671660

15. Innes KE, Selfe TK. Yoga for adults with type 2 diabetes: A systematic review of controlled trials. J Diabetes Res. 2016;2016:10-2. https://doi.org/10.1155/2016/6979370 PMid:26788520

16. Jayawardena $R$. The benefits of yoga practice compared to physical exercise in the management of Type 2 diabetes mellitus: A systematic review and metaanalysis. J Chem Inf Model. 2018;53(9):1689-99.

17. Hengchang $\mathrm{H}$. Evaluation of walking exercise on glycemic control in patients with type 2 diabetes mellitus: A protocol for systematic review and meta-analysis of randomized cross-over controlled trials. Medicine (Baltimore). 2020;99(47):e22735. https://doi.org/10.1097/MD.0000000000022735 PMid:33217794

18. Venugopal V, Rathi A, Raghuram N. Effect of short-term yoga-based lifestyle intervention on plasma glucose levels in individuals with diabetes and pre-diabetes in the community. Diabetes Metab Syndr Clin Res Rev. 2017;11(2):S597-9. https:// doi.org/10.1016/j.dsx.2017.04.010

PMid:28420577

19. Karstoft K, Clark MA, Jakobsen I, Müller IA, Pedersen BK, Solomon TP, et al. The effects of 2 weeks of interval vs continuous walking training on glycaemic control and whole-body oxidative stress in individuals with Type 2 diabetes: A controlled, randomised, crossover trial. Diabetologia. 2017;60(3):508-17. https://doi.org/10.1007/s00125-016-4170-6 PMid:27942800

20. Qiu S, Cai X, Sun Z, Zügel M, Steinacker JM, Schumann U. Aerobic interval training and cardiometabolic health in patients with type 2 diabetes: A meta-analysis. Front Physiol. 2017;8:1-11. https://doi.org/10.3389/fphys.2017.00957 PMid:29218018

21. Jung HY, Lee H, Park J. Comparison of the effects of Korean mindfulness-based stress reduction, walking, and patient education in diabetes mellitus. Nurs Health Sci. 2015;17(4):516-25. https://doi.org/10.1111/nhs.12229 PMid:26275164

22. You H, Gao T, Cooper TK, Reeves WB, Awad AS. Macrophages directly mediate diabetic renal injury. Am J Physiol Ren Physiol. 2013;305(12):1719-27. https://doi.org/10.1152/ ajprenal.00141.2013 PMid:24173355

23. Brugada J, Blom N, Sarquella-Brugada G, BlomstromLundqvist C, Deanfield J, Janousek J, et al. Pharmacologica and non-pharmacological therapy for arrhythmias in the pediatric population: EHRA and AEPC-Arrhythmia Working Group joint consensus statement. Europace. 2013;15(9):1337-82. https:// doi.org/10.1093/europace/eut082

PMid:23851511 